International Journal of Trend in Scientific Research and Development (IJTSRD)

Volume: 3 | Issue: 3 | Mar-Apr 2019 Available Online: www.ijtsrd.com e-ISSN: 2456 - 6470

\title{
Dynamic Analysis of Bionic ARM
}

\author{
Mr. M. Sreedhar ${ }^{1}$, Mrs. P. Varalakshmi' ${ }^{1}$, R. Naveen ${ }^{2}$, S. Bharath Kumar ${ }^{2}$, T. Akhil Reddy ${ }^{2}$ \\ ${ }^{1}$ Assistant Professor, ${ }^{2}$ Student \\ 1,2Department of Mechanical Engineering, Guru Nanak Institute of Technology, Hyderabad, India
}

\begin{abstract}
How to cite this paper: Mr. M. Sreedhar | Mrs. P. Varalakshmi | R. Naveen | S. Bharath Kumar | T. Akhil Reddy "Dynamic Analysis of Bionic ARM" Published in International Journal of Trend in Scientific Research and Development (ijtsrd), ISSN: 24566470, Volume-3 | Issue-3 , April 2019, pp.1176-1179, URL: https://www.ijtsrd.c om/papers/ijtsrd23 237.pdf

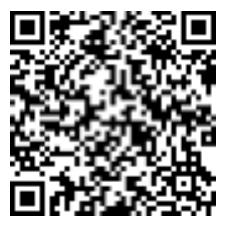
IITSRD23237
\end{abstract}

Copyright (C) 2019 by author(s) and International Journal of Trend in Scientific Research and Development Journal. This is an Open Access article distributed under the terms of the Creative Commons

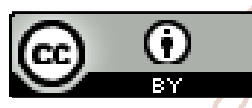
Attribution License (CC BY 4.0) (http://creativecommons.org/licenses/ by/4.0)

\section{INTRODUCTION}

The term bionic is combination of two words biology and mechanics, which gives the function of mechanics through biological inputs. Bionic arm is a best revolution ides for the amputees across the world. This is as close as we can get to our natural limb. The main objective is to make the arm move with our brain unlike prosthetics that are robotic controlled. In case of bionic arm we take the nerve signals from brain and amplify it so that we can register the signal and convert that electrical signal to mechanical energy so as to move the mechanical device. The arm prosthesis is being used and constantly being perfected to suit human needs. Various types of prosthetic have been made to suit many actions but not all. But the bionic arm will be able to perform all the human limbs. a bionic arm combines robotics, biotechnology, and electronics to recreate the functions of the human arm. Advances in bionics can improve the lives of millions of people with lost limbs. In this challenge you will design and test a robotic arm, and learn how engineers create working artificial arms. This project aims at developing a neuro-controlled hand prosthesis design part and the analysis of the prototype. [1]

\subsection{Prosthesis}

In medicine, prosthesis is an artificial extension that replaces a missing body part. It is part of the field of bio mechatronics. Prosthesis are typically used to replace parts lost by injury or missing form birth or to supplement defective body part.[2]

\section{ABSTRACT}

In this day and age there is an expanding need to make artificial arms for various cruel circumstances where human communication is troublesome or incomprehensible. They may include taking readings from a dynamic spring of The prototype is converted into standard for the exchange of product (stp) file and is imported in the ANSYS software for the calculation of parameters such as strength. The fingers are revolute pairs that are free to rotate about certain degrees; this motion is given by actuators. The arm can be improvised by using

KEYWORDS:-incomprehensible, gushing, degree offreedom, optimization, mimics.

\subsection{Mechatronics}

Mechatronics is the combination of mechanical engineering, electrical engineering, computer engineering and control systems.[2]

\subsection{Bio mechatronics}

Bio mechatronics is the merging of man with machine-like the cyborg of science fiction. It is an interdisciplinary field encompassing biology, neuroscience, mechanics, electronics, and robotics. The biomechanics focuses the interactivity of the brain with the electromechanical devices and the systems.[3]

\subsection{Bio mechatronic hand}

An ideal artificial hand should match the requirements of prosthesis and humanoid robotics. It can be wearable by the user which means that it can be perceived as part of the natural body and should replicate sensory-motor capabilities of the natural hand. This means that the artificial hand should be felt by the user as the part of his $\backslash$ her own body and it should provide the user with the same functions of natural hand.[4]

\subsection{Bio sensors}

Biosensors are used to detect the user intensions and to do the require functions. Ion some devices the information can be relayed by the users nervous system or muscle system. This information is related with both bio sensor and the controller. Biosensors are in different forms such as needle implants, wired that detect nerve signals and electrode arrays with nerves growing through them. [4] 


\subsection{Controller}

The controller in a bio mechatronic device is similar to bio sensors that relays the user intentions and send the inputs to actuators. It also interprets feedback information to the user that comes from the bio sensors and mechanical sensors. It also controls the device's movements.[5]

\subsection{Actuators}

The actuator is an artificial muscle that produces force and movement to the joints. Depending upon the device the actuator can be of different type such as motor assisted, gear assisted, tendon drive and etc...[5]

\subsection{Natural Hands}

These are the chief organs for physically manipulating the environment, used for both gross motor skills such as grasping a large object and fine motor skills such as grasping a small object. The fingertip contains some densest areas of nerve endings on the body, are the richest source of tactile feedback that senses the heat, roughness of a body, state of the body. The sense of touch is immediately associated with brain and is taken action against the action of the hand. [5]

\subsection{How Bionic Hand Works}

Bio mechatronics devises have to be based on how the human body works for example four different steps must occur to be able to lift the foot to walk first impulse from the motor center of the brain are sent to the foot and legs muscles next the nerve cells in the feet send information to the brain telling it to adjust the muscle groups or amount of force required to walk across ground different amounts of forces are applied depending on the type of surface being walked [6]

\section{Materials Used In Bionic Arm}

A prosthetic should consist of following parameters in order to most reliable and good handling, it should be lightweight; hence most of prosthetic devices are made from plastic. Metals such as titanium and aluminum are also used in prosthetics such that more strength and toughness and is available in it. These materials replaced much of steel in the pylon which is more weight. Now a days alloys of materials and composite materials are used in the prosthetic devices.[7]

\subsection{Nano Composite Materials For Prosthetic Devices} Nanotechnology is the prosperous areas of development in material sciences by the current researchers, this is also a greatest development in medical sciences the word nano means dwarf which is derived from Greece.[7]

\subsection{Classification Of Nano Composites}

On the basis of composition of materials

$>$ Non polymer based composites, mad

$>$ Polymer based composites

\subsubsection{Non Polymer Based Nano Composites}

The components of nano materials which do not contain polymer based materials in its composition formula. These are further classified in to

$>$ Metal-metal nano composites

$>$ Metal-ceramic nano composites

$>$ Ceramic-ceramic nano composites[7]
The nano composites that mostly contain polymer materials in its composition formula. Some of those are

$>$ Polymer-polymer nano composites

$>$ Polymer-ceramic nano composites

$>$ Inorganic-organic polymer based nano composites

$>$ Inorganic-organic polymer based nano composites

$>$ Inorganic half and half nano composites

$>$ Polymer-layered silicate nano composites

\subsection{General Materials Used In Prosthetic Devices}

Materials used in prosthetic devices are should be of light weight, high strength, and good resistant to temperature

\subsection{Acrylonitrile Butadiene Styrene}

It is a common thermo plastic polymer. It is also called as ABS. glass transition temperature is about 105 degrees Celsius. ABS is amorphous and has no true melting point.

\subsection{Polypropylene}

A thermoplastic polymer used in wide variety of applications which is produced via chain growth polymerization. The monomer in this chain polymer is propylene.

\subsection{Nylon 6,6 Polymer}

It belongs to the class of amides, there are many types of nylon; the two most used in plastic industries are nylon 6 and nylon 6,6. The monomers included in nylon 6,6 are hexa methylene di amine and adipic acid.

\subsection{Plexiglas}

Poly methyl meth acrylate, it is also known as acrylic glass and some more trade names as cry lux, Perspex, etc...It is a light weight material, resistant to shatter and transparent thermoplastic material. It is used in inks and coatings.

2.8 Properties Of Materials Used In Bionic Arm

\begin{tabular}{|c|c|c|}
\hline $\begin{array}{l}\text { S. } \\
\text { No }\end{array}$ & Materials & Properties \\
\hline 1 & $\begin{array}{l}\text { Acrylonitrile } \\
\text { butadiene } \\
\text { styrene }\end{array}$ & $\begin{array}{l}\text { Melting temperature:- } 210^{\circ} \mathrm{C}[8] \\
\text { Tensile strength: } 44.81 \mathrm{MPa}[8] \\
\text { Modulus of elasticity:3100MPa[8] } \\
\text { Density: } 1.01 \mathrm{~g} / \mathrm{m}^{3}[8] \\
\text { Poison's ratio: } 0.35[9] \\
\text { Shrinkage: } 8 \%[8]\end{array}$ \\
\hline 2 & Polypropylene & $\begin{array}{l}\text { Melting temperature: } 168^{\circ} \mathrm{C}[10] \\
\text { Tensile strength: } 48 \mathrm{MPa}[10] \\
\text { Modulus of elasticity:200MPa[10] } \\
\text { Density: } 946 \mathrm{~kg} / \mathrm{m}^{2}[10] \\
\text { Poison's ratio: } 0.43[10] \\
\text { Fatigue strength: } 30 \mathrm{MPa}[10]\end{array}$ \\
\hline 3 & $\begin{array}{l}\text { Nylon 6,6 } \\
\text { polymer }\end{array}$ & $\begin{array}{l}\text { Melting temperature: } 265^{\circ} \mathrm{C}[11] \\
\text { Tensile strength: } 124 \mathrm{MPa}[11] \\
\text { Modulus of elasticity: } \\
2930271807 \mathrm{~N} / \mathrm{m}^{2}[12] \\
\text { Density: } 1.14 \mathrm{~g} / \mathrm{m}^{3}[11] \\
\text { Poison's ratio:0.39[13] } \\
\text { Fatigue strength: } 41 \mathrm{MPa}[11]\end{array}$ \\
\hline 4 & Plexiglas & $\begin{array}{l}\text { Melting temperature: } 160^{\circ} \mathrm{C}[14] \\
\text { Tensile strength: } 80 \mathrm{MPa}[14] \\
\text { Modulus of } \\
\text { elasticity: } 3300 \mathrm{MPa}[14] \\
\text { Density: } 1.19 \mathrm{~g} / \mathrm{cm}^{3}[15] \\
\text { Poison's ratio:0.37[15] } \\
\text { Yield strength:110MPa[14] }\end{array}$ \\
\hline
\end{tabular}

\subsubsection{Polymer Based Nano Composites}




\subsection{Structural analysis}

Few types of static structural methods are available one of them is material strength analysis which is also known as classic analysis. This method is generally used ion where complex shapes are available; like robotic parts which require tedious and difficult calculations the calculations are mostly based on assumptions. These calculations lead to development of finite element analysis (FEA). These are solved by applying boundary conditions and loads gives thus obtaining the solution for the given problem.[16]

\subsection{Strength of material}

Every static or dynamic body contain some natural deformation when is subjected to some type of load or force. However, the resistive force is applied against to the actual force due to the cohesion between the molecules. This resistive strength is categorized as stress and strain. Stress ions defined as the amount of resistive force per unit area where strain is defined as the change in dimension to the original dimension due to actual force. There are few types of strains named as tensile, compressive, shear volumetric. [16]

\subsection{Finite element analysis}

FEA is complex task that performs numerous calculations and iterations to get optimized and nearest possible solution for a given problem statement. ANSYS is a software that perform finite element analysis tasks based on computer programming.[16]

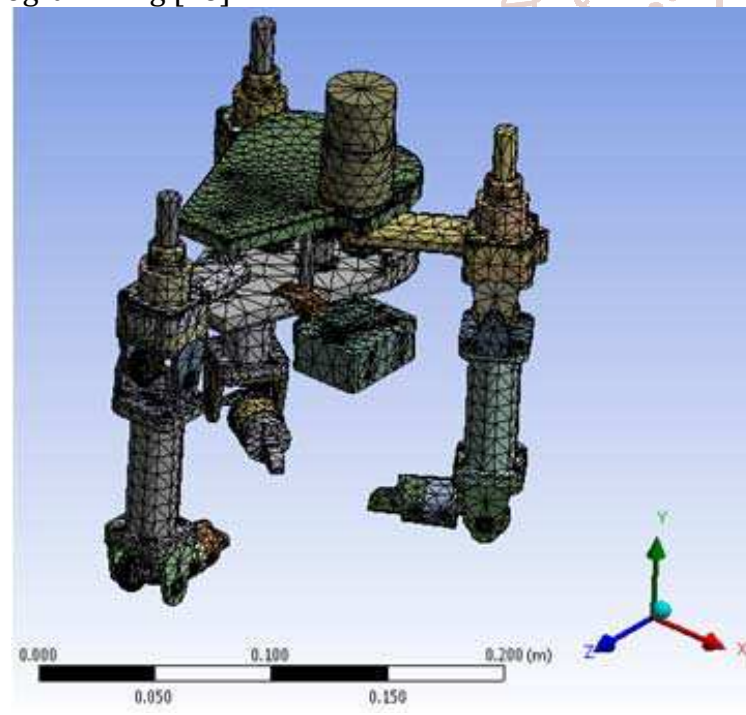

Figure 1 Mesh of the bionic hand[16]

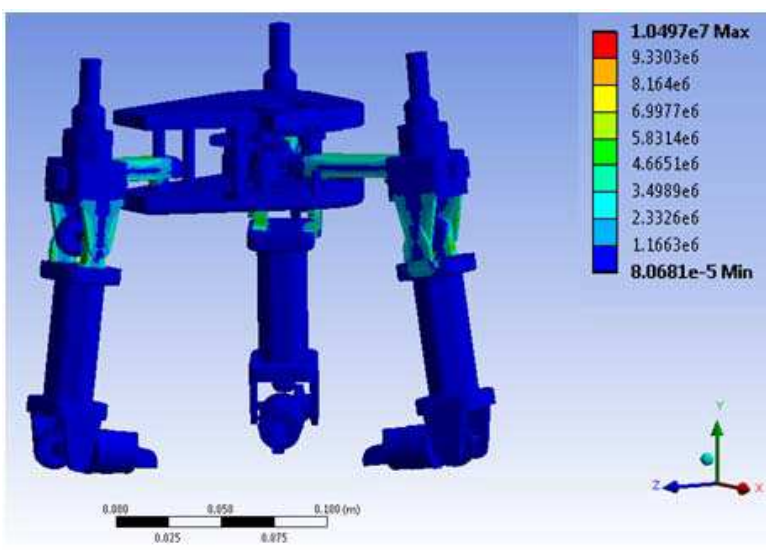

Figure 2 Equivalent (Von-Mises) stress[16]

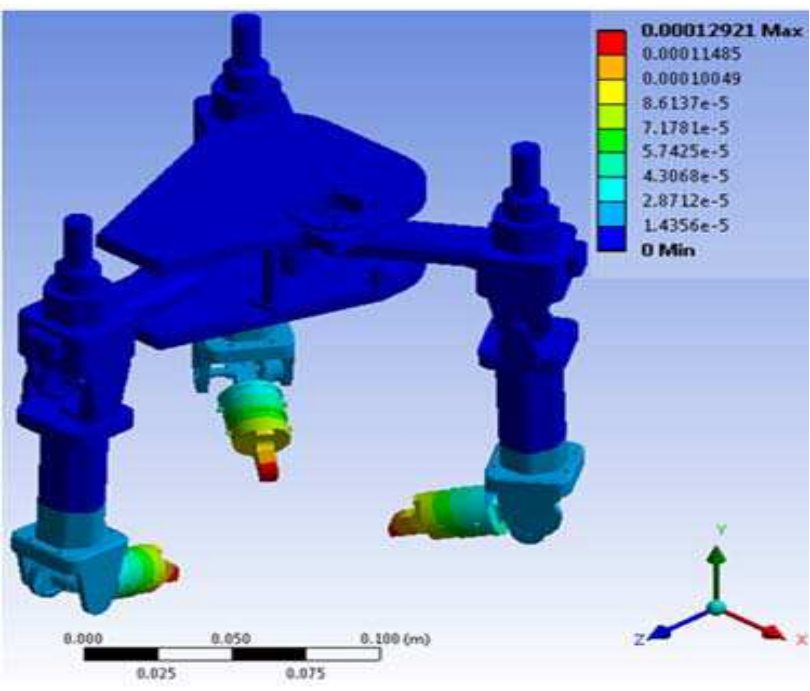

Figure 3 Deformation[16]

\subsection{Evolution of grasping force}

Grasping force is tendency to hold an object that may just touch the object or lift the object against gravity. Robotic grasp is strongly related to design of fixtures in the robotic parts that is good enough to do the job. Grasp planning includes the contact point of fingers for different objects with different configurations, for example holding a cylinder with a robotic arm is possible by four fingers excluding thumb whereas for a sphere like object thumb is used and the contact point of finger may change. Some of the grasp properties are[17]

\subsubsection{Disturbance resistance}

A grasp can resist disturbances in any direction either by finger positioning and immobility in the grasp in such cases the main problem is determination of contact point of fingers for complex objects.[17]

\subsubsection{Dexterity}

A grasp is dexterous if the hand can move the object in a compatible way with the task to be performed. When there are no task specifications, a grasp is considered dexterous if the hand is able to move the object in any direction.[17]

\subsubsection{Equilibrium}

A grasp is equilibrium if the some of forces is null in all directions.[17]

\subsubsection{Stability}

A grasp is stable if any error in the object position caused by a disturbance disappears in time after the disturbance vanishes.[17]

\section{Conclusion}

Bionics are used in wide variety of applications, mostly humans use this medics to relief them from getting depression for being lost of body parts. This paper concludes the types of materials that are used in prosthesis depending upon the work determination for example, a fire extinguisher prosthetic should be of material with high temperature resistant and a prosthetic that deals with fluids are of corrosion resistant. Deformation caused, stresses, strains are also developed in the hand are also evaluated. 
International Journal of Trend in Scientific Research and Development (IJTSRD) @ www.ijtsrd.com eISSN: 2456-6470

\section{References}

[1] https://www.openbionics.org/\#designs

[2] tushar kulakarni, rashmi uddanwadiker, Dept. of mechanical engineering, visvesvaraya national institute of technology, nagpur

[3] R. G. E. Clement*, K.E. Bugler, C.W. Oliver Department of Trauma and Orthopaedics, Royal Infirmary of Edinburgh, 51 Little France Crescent, Old Dalkeith Road, Edinburgh EH16 4SA, UK

[4] Carrozza, M. C., Micera, S., Massa, B., Zecca, M., Lazzarini, R., Canelli, N., \& Dario, P. (n.d.). The development of a novel biomechatronic hand-ongoing research and preliminary results. 2001 IEEE/ASME International Conference on Advanced Intelligent Mechatronics. Proceedings (Cat. No.01TH8556). doi:10.1109/aim.2001.936462

[5] Gauthaam, M., \& Sathish Kumar, S. (2011). EMG controlled bionic arm. 2011 National Conference on Innovations in

Emerging Technology.doi:10.1109/ncoiet.2011.5738813

[6] Rutvij B. Mavani, Dharmik H. Rank, Helina N. Sheth BioMedical Engineering, GEC Gandhinagar, Gujarat (C) 2014 IJEDR | Volume 2, Issue 3 | ISSN: 2321-9939

[7] Hasnain, M. S., Ahmad, S. A., Minhaj, M. A., Ara, T. J., \& Nayak, A. K. (2019). Nano composite materials for prosthetic devices. Applications of Nano composite Materials in Orthopedics, 127-144.doi:10.1016/b9780-12-813740-6.00007-7
[8] http://vexmatech.com/abs-material.html

[9] https://www.engineersedge.com/plastic/materials_co mmon_plastic.htm

[10] Hisham A. Maddah $1,2{ }^{1}$ Department of Chemical Engineering, King Abdulaziz University, Rabigh, Saudi Arabia ${ }^{2}$ Department of Chemical Engineering, University of Southern California, Los Angeles, United States

[11] Emco industrial plastics, Inc.

[12] https://www.plexiglas.de/product/plexiglas/en/about /faq/pages/properties.aspx

[13] https://www.pentagonplastics.co.uk/wpcontent/uploa ds/2015/04/Nylon-PA66.pdf

[14] https://www.creativemechanisms.com/blog/injectionmold-3d-print-cnc-acrylic-plastic-pmma

[15] https://www.plexiglas.de/product/plexiglas/en/about /faq/pages/properties.aspx

[16] Muhammad Hafiz bin Mohamed Azri, Ruhizan Liza Ahmad Shauri Faculty of Electrical Engineering Universiti Teknologi MARA Malaysia 40450 Shah Alam, Selangor, Malaysia 2014 IEEE 4th International Conference on System Engineering and Technology (ICSET) November 24-25, 2014 Bandung - Indonesia

[17] Máximo A. Roa · Raúl SuárezReceived: 1 March 2013 / Accepted: 4 July 2014 / Published online: 31 July 2014(C) The Author(s) 2014. This article is published with open access at Springerlink.com 